\title{
Sharing killed the AVMSD star: the impossibility of European audiovisual media regulation in the era of the sharing economy
}

\author{
Indrek Ibrus \\ Baltic Film, Media, Arts and Communication School (BFM), Tallinn University, Estonia, \\ indrek.ibrus@tlu.ee

\section{Ulrike Rohn} \\ Baltic Film, Media, Arts and Communication School (BFM), Tallinn University, Estonia, \\ ulrike.rohn@tlu.ee
}

Published on 30 Jun 2016 | DOI: 10.14763/2016.2.419

\begin{abstract}
The paper focuses on the challenges that the 'sharing economy' presents to the updating of the European Union's (EU) Audiovisual Media Service Directive (AVMSD), part of the broader Digital Single Market (DSM) strategy of the EU. It suggests that the convergence of media markets and the emergence of video-sharing platforms may make the existing regulative tradition obsolete. It demonstrates an emergent need for regulatory convergence - AVMSD to create equal terms for all technical forms of content distribution. It then shows how the operational logic of video-sharing platforms undermines the AVMSD logic aimed at creating demand for professionally produced European content - leading potentially to the liberalisation of the EU audiovisual services market. Lastly, it argues that the DSM strategy combined with sharing-related network effects may facilitate the evolution of the oligopolistic structure in the EU audiovisual market, potentially harmful for cultural diversity.
\end{abstract}

Keywords: Audiovisual media, Sharing economy, Video-sharing

\section{Article information}

Received: 01 Feb 2016 Reviewed: 12 Apr 2016 Published: 30 Jun 2016

Licence: Creative Commons Attribution 3.0 Germany

Funding: This work was supported by the Estonian Research Council grant PUT (1176).

Competing interests: The author has declared that no competing interests exist that have influenced the text.

URL:

http://policyreview.info/articles/analysis/sharing-killed-avmsd-star-impossibility-european-audiovisual -media-regulation-era

Citation: Ibrus, I. \& Rohn, U. (2016). Sharing killed the AVMSD star: the impossibility of European audiovisual media regulation in the era of the sharing economy. Internet Policy Review, 5(2). https://doi.org/10.14763/2016.2.419

This paper is part of Regulating the sharing economy, a special issue of Internet Policy Review guest-edited by Kristofer Erickson and Inge Sørensen. 


\section{DEFINING SHARING ECONOMY}

The 'sharing economy' is a concept that has received a lot of attention in both academic and popular writing in recent years (e.g., Botsman and Rogers, 2010; Cohen and Kietzmann, 2014; Nicholas A. John, 2012; Rosen, Lafontaine and Hendrickson, 2011). Yet, very rarely has this concept been discussed in the context of media services. In this article we will demonstrate the relevance of the sharing economy concept for understanding contemporary changes in media markets and, especially, how content sharing practices may undermine the existing policy frameworks that regulate these markets. In particular, we demonstrate how online video sharing practices are incompatible with and may challenge the updating of the European Union's (EU) core regulative instrument, the Audiovisual Media Services Directive (AVMSD). The AVMSD is understood to have facilitated recent successful export of audiovisual content by European producers, which could now be at risk. Furthermore, the article seeks to demonstrate how new video sharing practices could also lead to concentration of media markets in the EU due to 'network effects' present in sharing platforms. This outcome would contradict the general perception of the sharing economy as facilitating more effective coordination, inclusivity and plurality in markets.

Before discussing the effects of the sharing economy for EU media policy let us first define this phenomenon more broadly and then in relation to the specifics of media markets. The sharing economy is generally characterised as an exchange practice where economic agents do not purchase properties to own them, but rather where the sharing of these properties among them is the prevalent trend. In a sharing economy, having access to something is more important than owning it (Belk, 2014). Yet, is the sharing economy altogether new? This is questioned since the sharing of resources among members of a society can be seen as one of the oldest forms of economic governance. Indeed, as Baldwin and von Hippel (2009) indicate, due to the very high production and communication costs, sharing was one of the main forms of economic governance in ancient and agricultural societies. Whereas industrialisation conditioned firmdriven production and markets in the industrial era, the steep decrease of design and communication costs in the network society has facilitated the emergence of so-called hybrid economies, in which non-market activities, such as the sharing of skills, labour, assets or knowledge, often without the accompanying exchange of money, have become important components of the emergent societal order and new economic relationships. In the network society, users of social media platforms such as Facebook and YouTube share information and media content with each other, while on platforms such as Airbnb or Uber, they 'share' their accommodation or cars. Networked communications and social media platforms are therefore characterised by low communication costs, which have enabled new forms of connection making, cooperation and sharing between economic agents on the global scale (Rifkin, 2014). As John (2013) points out, sharing is the fundamental and constitutive activity of Web 2.o.

On the other hand, various new operations that rely on the Web 2.o logic of coordinating the actions of network participants and marketing their operations as 'sharing' are, as demonstrated by Slee (2015), potentially about organising established services differently in order to circumvent existing market regulations. Such activities tend to result in harsh free-market practices being extended into previously protected areas of people's lives, also pushing vulnerable individuals to take on unsustainable risk. The non-market activities that would actually justify the term 'sharing' in these operations are often very minimal. Therefore, services such as Uber are in reality just expressions of neoliberal capitalism under the mask of the 
sharing economy.

\section{THE SHARING ECONOMY IN THE MEDIA}

Whether similar concerns could also be raised about the media and other content industries is, however, a stimulating question. For answering this we need to distinguish between different kinds of sharing. According to John (2013) sharing economies can be either of consumption or of production and this applies also to the media field.

In terms of sharing economies of production or 'collaborative production', what is relevant for the media and content industries is that networked technologies enable interested parties to 'share' their labour - i.e., to work for free in the content production or service development processes (see also Terranova, 2004). This usually means that fans or other interested users participate in creating and editing media content on a large scale (see also Bruns, 2012). As Von Hippel (2005) has demonstrated, there is a range of rationales for people to contribute their labour including enhancement to reputation in specific communities and the potential positive network effects to that reputation if the particular product gains traction.

What is important, however, is that such rationales and activities contribute to the production of culture and knowledge outside the traditional market (Benkler, 2006). Yet, paradoxically, any audience member who shares data, information or content with content-producing companies can thereby be said to participate in the company's production and value creation processes. Practices of crowdsourcing (Howe, 2009) and citizen journalism (Allan and Thorsen, 2009; Goode, 2009), where audience members actively participate in the acquisition and creation of content, are forms of collaborative production and expressions of a sharing economy in the media field.

Sharing economies of consumption may include collaborative forms of content consumption through the re-distribution and spreading of content among peer-to-peer networks or through any form of social networking as part of a shared media experience, as, for instance, discussed under the headline of social TV (Botsman and Rogers, 2010; Noam and Pupillo, 2008; Pagani and Mirabello, 2011). Yet, while sharing economies of production are generally celebrated for their potentially democratising effects the sharing economies of consumption are perceived as more controversial. The views on free content sharing are often ideologically charged in terms of their impact on the societal order and development as well as on cultural evolution. The different views on content sharing by audiences become clear when we consider that audience members that practice free sharing can be conceptualised both as citizens and as consumers.

First, when we conceptualise the audiences and users as 'citizens', i.e., political and social agents, then content sharing, even without the consent of intellectual property rights owners, is often viewed in popular discourse as being associated with freedom of speech and the free exchange of knowledge by all and to all. Such an exchange is expected to facilitate the 'democratization of innovation' (von Hippel, 2005) and therefore also more innovation, followed by more development, economic growth, cultural diversity and potentially a more equal distribution of wealth in society. Most importantly, the capability to share and, therefore, also to access knowledge freely is seen as translating into citizen empowerment and the widespread distribution of agency. It is, therefore, often claimed that the sharing of knowledge in the form of access to content may be good for the polity, i.e. for the effective functioning of contemporary societies. There has been a consensus forming among policymakers that, as much 
as possible, new policy frameworks should enable free sharing of new knowledge - especially government funded research results, academic articles, etc. (European Commission, 2016b).

Second, when we define audiences and users as 'consumers', i.e. economic agents, then the general tone often turns more negative, where the sharing of content as a violation of copyright is seen to harm the media and other content industries (although evidence to this has been disputed, see Mansell and Steinmueller, 2013). In this context it should be emphasised that the sharing of content usually does not involve the turning over of the property rights. The logic behind intellectual property rights (IPR) means that in the case of content 'sharing', what is really shared is access to the content, thus enabling its consumption with regard to specific circumstances (e.g., on specific platforms, within a specific timeframe, etc.). Therefore, the sharing of content does not mean that the owner of the property, as a rule, needs to tolerate the risk of losing it, other than the risk of potentially needing to change how the particular property is made to generate returns for its owner.

Yet, there are plenty of examples where especially audiovisual media industry losses from peerto-peer sharing have been calculated to be colossal, content sharing has been criminalised and countries have moved towards hardening the penalties. This is despite the fact that young sharers of media content are often unaware of the illegality of their actions and may be driven by reciprocity (Becker and Clement, 2009). Still, relevant for the further discussion in this paper is that differently from some other content production sectors, in case of audiovisual media industries the policy work has mostly focused on minimising free sharing by audiences.

In parallel to this, also new perceptions have emerged from within the media industries. It is often realised that sharing of content properties by users may support new kinds of 'hybrid' business models that enable new ways for content owners to generate income (Lessig, 2008). That is, where there are heightened interests around particular media content, facilitated by a free sharing practice, this may be used for the additional monetisation of it in various forms. Very often, media organisations follow so-called freemium business models (Anderson, 2009), where they share content or parts of content for free in return for promotional sharing activities by audiences, but also in return for data on audience behaviour, which may be useful for the improvement of future content creation as well as for marketing purposes. Such a hybrid economy, conditioned by free sharing practices, is increasingly becoming the new normality in the media sector.

In-depth interviews by one of the authors with 25 audiovisual and print media providers in Estonia, Finland and Germany (carried out between 2011 and 2015), for instance, demonstrated that content providers are increasingly choosing to share their content or promotional material across a variety of online platforms (Rohn and Baumann, 2015). Through, for instance, sharing their videos freely on YouTube, companies hope to trigger further sharing behaviour by audiences. Over their interaction with audiences, companies hope to receive crucial information to help them improve their services. Therefore, various kinds of sharing practices are increasingly prevalent in the media industries.

\section{THE SHARING ECONOMY MAY CONTRIBUTE TO MEDIA CONCENTRATION}

What is also of crucial interest is to know where such sharing activities take place. As it became clear through the interviews, both content owners as well as the audiences prefer to utilise the 
few globally dominant platforms for their sharing practices. These include, above all, YouTube, Vimeo and Facebook. This means that the gatekeeping function for the sharing-based global societal dialogue is carried out by only a few service providers, mostly of North American origin.

What is the reason for this highly concentrated, oligopolistic market for platforms that enable sharing practices? We suggest that among the main conditioning factors is the phenomenon known as positive network externalities (also: network effects). The theory of network effects stems from economic theory and claims that the value of a network depends on its number of users (David and Greenstein, 1990; DiMaggio and Cohen, 2005; Katz and Shapiro, 1986; Rohlfs, 1974). Hence, due to network effects, the more members a platform for sharing purposes has, the more attractive it is for any of its users (Ahn, 2009; Cusumano, 2011; Kwon, 2011). A study by Rohn (2013), for instance, showed that Facebook is so popular because of its large membership, which further attracts users from different cultural and geographic background. Although not all members of Facebook may be relevant to a specific user, according to Reed's Law (Reed, 2001), the utility of a social network scales exponentially with its size, even if the direct number of contacts per individual is very small. Likewise, Skype, for instance, is more valuable to any of its individual users the more people use it on a steady basis. Hence, large, international platforms for sharing purposes benefit from network effects that no national or local platform could offer.

One problem with network effects is that such 'value pull' often leads to concentration in the specific markets, since the majority of consumers tend to prefer the most popular services. In the case of standard communications services, such as telephone or VoIP (Voice over Internet Protocol), this problem is mostly 'economic' - whereby monopolistic players may not serve society in the best or cheapest ways. Yet in the domain of media and culture, the concentration is also feared due to its potentially negative effects on cultural diversity or political pluralism.

Our suggestion is that network effects are highly relevant for markets affected by sharing practices since people share where there exists a potential for exchange with as many others as possible. For instance, users are likely to register their cars for ride-sharing on the most popular platform for this purpose and they are also likely to share media content on the platform that has the most users and most active interactions between contributors. Therefore, while the economies of scope and scale logic has traditionally conditioned media markets to slide towards oligopolistic structures, it may be suggested that the network effects of sharing practice may further contribute to the situation of only a handful of large online platforms controlling the global hybrid economies of the contemporary media and content sectors. We will discuss below the implications of this tendency for the design of EU's Digital Single Market strategy and the risks involved for EU's smaller member states and their media systems.

Market concentration with all its associated threats represents a classic challenge for media policy making anywhere in the world. But what exactly are these challenges this time as platforms such as YouTube are effectively nothing other than channels that enable content sharing practices by an unprecedented number of users from all over the world? As such, would they not, in fact, facilitate and promote cultural diversity? The problem is that as global platforms with a universalised approach, they are not designed to serve specific national cultures by taking into account their particularities. There is evidence, for instance, that when memory institutions, such as libraries or archives, use these platforms to share their historical audiovisual heritage content, then YouTube algorithms suggest to users only the most popular videos and make finding the less popular, but still highly valuable, videos often impossible or at least the search results unpredictable (Vonderau, 2015). Further, Vonderau (2016) 
demonstrated how YouTube's focus has changed over the years from facilitating sharing by individuals and servicing interactions within communities to streamlining consumption processes. As such, YouTube's new focus lies on a channel- and genre-oriented interaction design, centred on pushing content towards viewers with the help of an algorithm that prioritises videos with longer overall viewing sessions over those that receive more clicks. Vonderau (ibid.) suggests that today, YouTube's interface resembles that of Netflix, evoking television's programmed flow rather than, for instance, the interaction on a dating website that it imitated in its infancy.

This suggests, first, that such 'sharing economy' companies in media markets are moving towards decreasing the sharing component of their hybrid models. Second, in terms of John's (2013) distinction between a sharing economy of production and a sharing economy of consumption, we witness a gradual move from the first to the second. Thirdly, for policymakers regulating the sharing economy as something distinctly different from more traditional services of media content distribution, would be a difficult endeavour - content sharing is increasingly an element of hybrid offers of online service providers and any regulative framework will need to accommodate this. Lastly, if sharing contributes to positive network externalities and, therefore, also to the dominance of only a few platforms in any market then this constitutes a new challenge for media policy making, including the design of the Digital Single Market (DSM). We will elaborate on this in the rest of this article as we discuss the effects of the sharing practice on the market evolution in Europe as well as on the cultural diversity in the EU Digital Single Market and then analyse the ways to accommodate these trends with existing regulatory frameworks.

\section{THE IMPACT OF THE SHARING ECONOMY ON THE AUDIOVISUAL MEDIA SERVICES DIRECTIVE}

The DSM strategy initiated by the European Commission is set to be completed under JeanClaude Juncker's presidency by summer 2019.Therein, the EC seems broadly aware of the complexities of the sharing economy and the challenges faced in regulating it. In its communications in 2015, its representatives repeatedly stressed that, while the sharing economy through its increased consumer choices offers opportunities for increased efficiency, growth and jobs, it also raises new regulatory issues (European Commission, 2015a). The potential for the associated threats were articulated and inquired about in the EC public consultation in autumn 2015. Although the results of this consultation have not been presented by the time of writing this paper, the questions in the consultation indicate that the $\mathrm{EC}$ has been most concerned about the dissolving rights and obligations of both the providers and consumers of services; the weakening of employment and social rights for workers; the non-compliance with health and safety standards and regulations and the rise in undeclared work and the black economy; as well as the uncertainty related to the protection of personal data, etc.

These concerns relate mostly to other sectors than the media, but the same consultation addressed also the roles of dominant platforms and here the complexities of the contemporary media economy are certainly forming on the horizon. The consultation asks for transparency of the platforms and asks if the relationships between the suppliers of content and the platforms should be regulated by the EU or if self-regulation by platform operators should be trusted. Such dilemmas will have implications in the first place for the EU's Audiovisual Media Services Directive (European Commission, 2010). 
The AVMSD is the EU's regulatory instrument to design the single market for audiovisual media. That is, television in the first place, but it has implications also for the film sector. The existing version of the AVMSD has been in force since 2010 and has also started to lightly regulate video-on-demand (VOD) services. That is, there has been a graduated approach to audiovisual media regulation in Europe, involving strong regulations for broadcasting and light regulations for non-linear services. However, both the EC as well as the member states (Council of the European Union, 2014) have noted the further service convergence and the growth of online content consumption among audiences, which is motivating further regulatory convergence - leveling the terms for different content transmission methods - and therefore also the revision and updating of the AVMSD. The EC announced the updating of the AVMSD in 2015, carried out an associated REFIT (EC's Regulatory Fitness and Performance programme) analysis and conducted a related public consultation and other studies.2

One of the first conclusions of the review indicates that the majority of EU member states and interest groups see, indeed, the need for leveling the regulations for different transmission technologies and platforms. It is understood that the sector has already converged when it comes to all aspects of the value chain, e.g., consumption, distribution, production. Most media providers deploy various cross-media strategies and diversify their services across different distribution technologies, while most content travels across multiple platforms and most users access media content on a variety of channels or platforms (Ibrus and Scolari, 2012). In this situation, maintaining different regulatory regimes for different technologies would create unnecessary complications and unfair conditions for market participants. Hence, the consensus that emerged based on the public consultation that the regulations need to converge.

There are several challenges to this convergence. One is related to the incompatibility between the AVMSD and the EU's E-Commerce Directive. The core logic of the AVMSD is that media services are licensed by member states and therefore all audiovisual media should have a 'country of origin' in the EU. In parallel, the E-Commerce Directive maintains that business in the internet should not be based on member states issuing licenses - i.e. the right to provide any kind of service online should be made available and free to all. Furthermore, from the human rights perspective, the Council of Europe has repeatedly addressed that issuing licenses for a right to publish content on the internet would be harmful to freedom of expression. In this context it is often seen that video sharing services (as market based innovations that could be understood to contribute positively to the freedom of expression) should not be drawn under the scope of the AVMSD. The proposition that this paper elaborates below is that, indeed, the sharing practices on some media platforms pose a challenge that may make the entire tradition of audiovisual media policies in Europe obsolete.

The AVMSD has several rationales, but key is to overcome the fragmentation of the European media market and to coordinate the evolution of a European single market for audiovisual content. It does this by facilitating demand for European works in member countries, which it has done so far with relative success (Ibrus, 2016). Historically, US dominance in the international export markets for film and television content has been facilitated by its huge monolingual domestic market, which has enabled a rich generic variety in production and good average returns from the home market, which in combination has enabled a significant flexibility in export strategies (Hoskins and Mirus, 1988; Rohn, 2004). Historically, Europe, which is a conglomerate of fragmented small national markets, has not been able to compete with the flexibility and related market power of the North American distributors. But now the AVMSD (and the directives and conventions that preceded it), with its provisions that require $50 \%$ of the programmes of all European broadcasters to originate from Europe and 10\% of 
content to be commissioned from independent producers, has to some extent neutralised the limitations due to European market fragmentation. As one of the authors of this paper has argued (Ibrus, 2016), the increasing export of European content, such as Scandinavian drama series or UK TV formats, not only within Europe but also globally, has been expedited by the provisions of the AVMSD. In our country of residence, Estonia, the change over the last two decades has been visible and dramatic - American TV-series that once dominated the TV schedules have been replaced by drama content and other TV formats from different corners of Europe. AVMSD, therefore, has functioned as a market coordination mechanism that has facilitated the growth of demand for original European content and has encouraged European producers to invest in development, innovation and quality, which in turn has resulted in further demand in Europe and elsewhere.

The main question regarding the potential leveling of regulations for linear and non-linear audiovisual media is: how, at times of convergence, can one achieve the same or similarly positive results for the European audiovisual industry and culture? Current discussions indicate that this may be very difficult since extending the AVMSD logic to non-linear internationally provided VOD-services may not be possible, as the content of digital catalogues cannot be regulated similarly to linear broadcast programmes. This is mostly because these catalogues may be structured and used in very different ways. For instance, the provision of news and current affairs video content on generic news portals is, as a rule, constantly being updated and, therefore, what is prioritised is the most recent content. At the same time, Netflix, for instance, organises its catalogue of professionally produced material based on its dynamically changing genre-categories (Madrigal, 2014) and on users' previous choices. YouTube, in turn, is mostly a video-sharing service, where the content offered to users is based on their search queries and on previous activities on its website. In the latter context, trying to make sure that certain percentage of YouTube content is of 'European origin' or that $10 \%$ has been commissioned from independent providers would not make much sense.

With this we want to emphasise that it is especially the sharing model of YouTube and the like that are about to undermine the extension of the AVMSD model to non-linear media platforms. This leads to the question of whether it would be possible to distinguish in regulatory terms between 'sharing economy' platforms and more conventional 'curated' platforms? Indeed, the EU Commission thinks it is doable, since its proposal (European Commission, 2016a) for the updating of the AVMSD published in May 2016 includes a distinction between VOD providers and video-sharing platforms whereas the latter are generally not included into the scope of the AVMSD. Therefore, only "VOD providers" would have to make sure that $20 \%$ of their content is of European origin. We expect such distinguishing to become very difficult due to the dynamically changing operational models of online video content provision services. As was shown above, although Netflix and YouTube may be seen as opposites, with one offering subscription-based access to professionally produced content and the other offering free sharing by everybody, the latter has been becoming gradually closer to the first - it has started to aggregate content into subscription-based channels and is launching new forms of subscription/VOD-like services such as YouTube Red that offers professionally produced content commissioned by YouTube. Furthermore, there are plenty of services in Europe offering often various kinds of hybrid forms that combine elements, such as sharing, free viewing, subscription and content purchasing, to various degrees. We therefore suggest, that as sharing practices become an increasingly omnipresent element in the wider media ecology, it makes continuation of the existing regulatory tradition impossible. 


\section{RISK OF MARKET CONCENTRATION IN THE DIGITAL SINGLE MARKET}

The ways that sharing practices induce network effects and therefore media concentration in Europe is another challenge for the development of the DSM. This is related to another articulated aim of the DSM strategy - to minimise the 'unjustified geoblocking' practice by media service providers. That is, the practice of only enabling access to a media service from the national territories for which they control the copyright or have licenses. The EC commissioners immediately responsible for the DSM - Andrus Ansip and Günther Oettinger - have been critical of the practice of geoblocking, pointing out that the single market is not functioning well if the access to specific content services is not enabled across national boundaries. This discourse has not been well received by AV-industry representatives anywhere in Europe, since the territory-by-territory sales of rights have enabled them to fund filmmaking more effectively. In particular, the whole co-production model could be undermined, as it presumes coproduction parties receiving and then exploiting exclusive rights for specific European territories. Still, copyright legislation in Europe, as elsewhere, is based on international treaties, and its central principle is its territorial application, and therefore the EC's hands are somewhat tied as it cannot make rights holders issue pan-European licenses or the buyers to pay for such licenses. Still, in December 2015, the EC published a proposal (European Commission, 2015b) that suggested cross-border 'content portability' for limited (although unarticulated) periods, enabling Europeans with lawful access to specific services to use the same services unhindered when travelling. However, such practices when implemented may still resemble a form of 'passive sales' and may therefore undermine the content production industry's business models.

The problem here for cultural and media policymakers is not only that the audiovisual industry but also, in particular, the content production industry would suffer. Also the potential blurring of national media spaces may have a negative impact on the media industries of the member states and could potentially facilitate the emergence of very large players that could then dominate media service provision in all of the EU. Indeed, there is already plenty of evidence that media markets have a tendency to evolve towards oligopolistic structures (Doyle, 2013) and, therefore, the risk is that if indeed an unhindered digital single market was to be enabled, this too would be dominated by only a very small number of providers. This could be expected to happen due to many factors, including the economies of scope and scale logics that have traditionally favoured larger operations in media markets. However, in the network economy, what adds to this is the logic of 'network effects' that, as suggested earlier in this article, may support the evolution of the oligopolistic market structures and the further lock-in of such structures.

What is problematic with such potential development is that the platforms currently set to dominate the European digital market (YouTube, Netflix, Amazon, Hulu, etc.) are all of USAmerican origin (see also Cunningham and Silver, 2013). The problem is not specifically about who owns these companies, but simply about the nature of their existing business conduct, which does not seem to be oriented to facilitating cultural diversity in Europe, as their catalogues are dominated by American content (Grece, Lange, Schneeberger, and Valais, 2015). Regarding professionally produced content, such dominance of American content in their catalogues is due to these players usually having close relationships with the dominant USAmerican film and TV content distributors, such as Warner Bros., 2oth Century Fox and Sony Pictures Entertainment, whereby they are able to broker comprehensive and occasionally 
exclusive deals with them. In comparison, EU national players, such as the public service media institutions of smaller member states will, firstly, not be well placed to compete for licenses (Netflix has openly admitted to preferring exclusive global licenses - see Spangler, 2015) or, secondly, they will not be able to compete for audience attention when they may want to offer unique European content to audiences. When combined with the impossibility of making VOD providers offer any European content at all (as discussed above), this may be harmful for the curation of national media spaces and, therefore, for cultural diversity in Europe.

Interviews by one of the authors with audiovisual media providers in Estonia and Finland (the study referred to above) also indicated that although smaller European TV providers may enjoy the communication and promotional activities enabled by the sharing platforms, such as Facebook or YouTube, the existence of international, US-American online VOD platforms puts pressure on them to change their business models. Traditional broadcasters have long been aware that they need to also target online streaming audiences in addition to their traditional broadcast audience. Non-linear VOD platforms are increasingly changing audience behaviour and expectations and shaking up the traditional value proposition of TV providers (Rohn and Nylund, 2016). As such, audiences increasingly expect to be able to consume their media whenever they want and from wherever they want. However, being able to feed various distribution channels with dedicated content is not always possible for every traditional TV provider or may incur extra costs and efforts (Ibrus and Ojamaa, 2014). What is more, when companies use platforms such as YouTube or Facebook for promotion and distribution, they operate in an environment where the rules are defined by the respective platform and not by themselves.

Previous research (Rohn and Baumann, 2015) has shown that many media providers have experienced insecurity about how to best present their content and brands on such platforms and have felt uncomfortable about surrendering to such platforms. However, at the same time, companies feel the pressure to be present on these platforms as a way of remaining relevant and discoverable. The above-mentioned interviews demonstrate that much of the audiences' sharing activities of their content via internationally dominant platforms are tolerated in the light of the potential to create heightened attention for a media property, which could lead to further monetisation of the particular property. Likewise, companies share large amounts of content across a variety of platforms, but as the interviews revealed, they often have no long-term strategy on how to monetise such sharing activities. Furthermore, the sharing activities on their own platforms or websites have to compete with the sharing activities on the large US-owned sharing platforms that reach much larger audiences. That is, while traditional content providers usually operate and target audiences within their national borders, any initiative on their part in terms of setting up their own sharing platforms will fail to trigger the same network effects as global platforms do. For instance, the Finnish public broadcaster YLE launched in autumn 2015 a new platform called Yle Folk, with an aim to facilitate sharing processes among their audience members and to promote an exchange of cultural works within their audience community in Finland. Yle Folk is thus a media content sharing platform through which YLE encourages its audiences from around the country to submit original content that they created themselves. Therefore, Yle Folk can be seen as an initiative to take back culturally-relevant content sharing processes to a platform whose aim it is to facilitate content sharing relevant to the national cultural and media system - as opposed to having such sharing activities on a platform owned and operated by global companies who do not have the vitalisation of the national cultural and media exchange as one of their goals. It remains to be seen how such 'nationally oriented' sharing platforms will fare, but the fact that such a platform was launched is indicative of the tension between national and global media systems with regard to the sharing practice. 
While the purpose of the AVMSD has been to advance the cross-border market for television broadcasting services, it has also been about facilitating cultural diversity in Europe. Both the $\mathrm{EU}$ and national media policies have, in general, perceived national media institutions as the cornerstones of the polity, as a vital part of contemporary reflective societies (Beck, Giddens, and Lash, 1994) and as the central curators of the national cultural space. It is for this reason that European countries, as a rule, support public service media institutions and aim to make private media provide more quality European content - all with an aim to systematically raise the awareness of different perceptions of social, cultural and political realities everywhere in Europe, in order to facilitate greater reflection on 'European life' in different textual modalities. A presumption would be that in the era of collaborative content production and the sharing economy, the rationales of public service media would be strengthened and the scope of their activities deepened. However, our paper suggests that there is a risk that the DSM and the specific logic of the sharing economy may instead actually contribute to media concentration on the European scale, which conversely would limit the impact of national media systems. That is, on the broader scale, the cultural diversity in Europe may suffer.

\section{CONCLUSION}

The EU is seeking ways to update its core instruments of media regulation. At the heart of this endeavour is the AVMSD, but the broader framework for this is its DSM strategy, which means that also several other directives and instruments will be changed - all due to the perception that media convergence and related market developments are about to make existing regulations outdated and therefore unaccommodating to the contemporary situation. However, the convergence of the regulatory traditions of television on the one hand and the internet on the other promises to be challenging and is expected to bring about the dropping of one of the two. This is due to the very different rationales of these regulatory traditions - TV regulation being the domain of cultural policy making, while the related internet regulation in the EU, formulated in its E-Commerce Directive, is about the regulation of service markets, based mostly on economic rationales and aimed at safeguarding entrepreneurial freedoms in the internet space. Although the AVMSD (and its predecessors) have over time evolved towards economic rationales rather than cultural goals (Celsing, 2010; Jõesaar, 2015), important differences with the E-Commerce Directive have remained. The first of these is the question of whether countries could issue licenses for media services. Broadcasting services have always been licensed in Europe and in this tradition the AVMSD sets the terms for this practice, enabling countries to use this instrument to design their national media systems. The ECommerce Directive in parallel forbids any kind of licensing of activities or businesses on the internet. Furthermore, the Council of Europe has repeatedly addressed that issuing licenses for a right to publish content in the internet would be harmful for freedom of expression and therefore for human rights. This is in line with the broader perception of content sharing, described in the introduction, that free sharing promotes knowledge exchange and by extension a more democratic and more balanced evolution of societies.

The latter two regulative rationales - the perceived needs for entrepreneurial freedom and the freedom of expression - explain why 'sharing' as a practice could bring about the demise of the European tradition of audiovisual media regulation. On the one hand, there is a pressure for regulatory convergence, which in turn will likely bring about liberalisation in audiovisual media markets, thus leaving the national media systems of small European countries susceptible to buffeting by global market dynamics (Ibrus, 2015, 2016). Furthermore, as our article has 
demonstrated, sharing practice, as a component in the hybrid economies of contemporary media markets, is incompatible with the provisions of the AVMSD, which set specific terms for TV programmes and potentially for VOD catalogues in terms of requested proportions of European and independent works. What is more, we demonstrated that sharing practices may contribute to media concentration in the internet, bringing the European Digital Single Market potentially in conflict with the EU's media policy tradition, which has traditionally aimed at avoiding media concentration. That is, next to the benefits of the 'sharing culture' in media industries (i.e., the potential for democratisation and for more participatory forms of media production), there are also plenty of associated risks and, therefore, difficult challenges ahead with regard to new policy development in Europe as well as elsewhere. 


\section{REFERENCES}

Ahn, D.Y. (2009). A dynamic model of usage behavior and network effects in social network sites. Austin, Texas. Retrieved from

http://repositories.lib.utexas.edu/bitstream/handle/2152/7671/ahnd83949.pdf?sequence=2

Allan, S. \& Thorsen, E. (Eds.). (2009). Citizen journalism: Global perspectives. New York: Peter Lang.

Anderson, C. (2009). Free: The Future of a Radical Price. London: Random House.

Baldwin, C., \& von Hippel, E. (2009). Modeling a Paradigm Shift: From Producer Innovation to User and Open Collaborative Innovation (Working Paper No. 10-038). Harvard Business School. Retrieved from https://hbswk.hbs.edu/item/modeling-a-paradigm-shift-fromproducer-innovation-to-user-and-open-collaborative-innovation

Beck, U., Giddens, A. \& Lash, S. (1994). Reflexive Modernization: Politics, Tradition and Aesthetics in the Modern Social Order. Cambridge: Polity Press.

Becker, J. U. \& Clement, M. (2006). Dynamics of Illegal Participation in Peer-to-Peer Networks-Why Do People Illegally Share Media Files? Journal of Media Economics, 19(1), 723. doi:10.1207/s15327736me1901_2

Belk, R. (2014). You are what you can access: Sharing and collaborative consumption online. Journal of Business Research, 67, 1595-1600. doi:10.1016/j.jbusres.2013.10.001

Benkler, Y. (2006). The Wealth of Networks: How Social Production Transforms Markets and Freedom. New Haven: Yale University Press.

Botsman, R. \& Rogers, R. (2010). What's mine is yours: The rise of collaborative consumption. New York: Harper Business.

Bruns, A. (2008). Blogs, Wikipedia, Second Life and Beyond: From Production to Produsage. New York: Peter Lang.

Celsing, A (2010). Dealing with Change: Impact of Convergence on European Union Media Policy. In S. J. Drucker \& G. Gumpert (Eds.), Regulating Convergence (pp. 37-58). New York: Peter Lang.

Cohen, B. \& Kietzmann, J. (2014). Ride On! Mobility business models for the Sharing Economy. Organization \& Environment, 27(3), 279-296. doi:10.1177/1086026614546199

Council of the European Union. (2014). Council conclusions on European Audiovisual Policy in the Digital Era. Brussels. Retrieved from

http://www.consilium.europa.eu/uedocs/cms_data/docs/pressdata/en/educ/145950.pdf

Cunningham, S. \& Silver, J. (2013). Screen Distribution and the New King Kongs of the Online World. London: Palgrave Pivot.

Cusumano, M. A. (2011). Platform wars come to social media. Communications of the ACM, 54(4), 31-33. doi:10.1145/1924421.1924433

David, P. \& Greenstein, S. (1990). The economics of compatibility standards: An introduction to 
recent research. Economics of innovation and new technology, 1, 3-41.

doi:10.1080/10438599000000002

DiMaggio, P. J. \& Cohen, J. N. (2005). Information inequality and network externalities: A comparative study of the diffusion of television and the Internet. In V. Nee \& R. Swedberg (Eds.), Economic sociology of capitalism (pp. 227-267). Princeton, New Jersey: Princeton University Press.

Doyle, G. (2013). Understanding media economics. 2nd edition. London: Sage.

European Commission. (2010). Audiovisual Media Services Directive. 2010/13/EU. Brussels. Retrieved from

http://eur-lex.europa.eu/legal-content/EN/TXT/PDF/?uri=CELEX:32010Loo13\&from=EN

European Commission. (2015a). A Digital Single Market Strategy For Europe. Brussels.

Retrieved from

http://ec.europa.eu/priorities/digital-single-market/docs/dsm-communication_en.pdf.

European Commission. (2015b). Proposal for a regulation of the European Parliament and the Council on ensuring the cross-border portability of online content services in the internal market. COM(2015) 627 final. Brussels. Retrieved from

http://ec.europa.eu/newsroom/dae/document.cfm?action=display\&doc_id=12524.

European Commission (2016a). Proposal for a directive of the European Parliament and of the Council amending Directive 2010/13/EU on the coordination of certain provisions laid down by law, regulation or administrative action in Member States concerning the provision of audiovisual media services in view of changing market realities. COM(2016) 287 final. Brussels. Retrieved from

http://eur-lex.europa.eu/legal-content/EN/TXT/PDF/?uri=CELEX:52016PCo287\&from=EN

European Commission (2016b). Open innovation, open science, open to the world: A vision for Europe. Luxembourg: Publications Office of the European Union. Retrieved from http://bookshop.europa.eu/en/open-innovation-open-science-open-to-the-world-pbKIo416263 /

Goode, L. (2009). Social news, citizen journalism and democracy. New Media \& Society, 11(8), 1287-1305. doi:10.1177/1461444809341393

Grece, C., Lange, A., Schneeberger, A., \& Valais, S. (2015). The development of the European market for on-demand audiovisual services. Strasbourg: European Audiovisual Observatory. Retrieved from https://ec.europa.eu/digital-agenda/en/news/development-european-marketdemand-audiovisual-services

Hoskins, C. \& Mirus, R. (1988). Reasons for the US dominance of the international trade in television programmes. Media, Culture \& Society, 10(4), 499-515.

doi:10.1177/016344388010004006

Howe, J. (2009). Crowdsourcing: Why the power of the crowd is driving the future of business. New York: Crown Publishing.

Ibrus, I. (2015). Audiovisual Policymaking in Estonia at Times of Convergence: An 'Innovation System' as a Policy Rationale. Baltic Screen Media Review, 3, 102-115. doi:10.1515/bsmr-2015- 
Sharing killed the AVMSD star: the impossibility of European audiovisual media regulation in the era of the sharing economy

0026

Ibrus, I. (2016). The EU Digital Single Market as a Mission Impossible: Audiovisual policy conflicts for Estonia. International Journal of Digital Television, 7(1), 23-38.

doi:10.1386/jdtv.7.1.23_1

Ibrus, I. \& Ojamaa, M. (2014). What Is the Cultural Function and Value of European Transmedia Independents? International Journal of Communication, 8, 2283-2300. Retrieved from http://ijoc.org/index.php/ijoc/article/view/2650

Ibrus, I. \& Scolari, C. A. (2012). Introduction: Crossmedia Innovation? In I. Ibrus \& C. A. Scolari (Eds.), Crossmedia Innovations: Texts, Markets, Institutions (pp. 7-21). Frankfurt: Peter Lang.

Jõesaar, A. (2015). Undercurrents of the Estonian Broadcasting Regulation, 1992-2014 Baltic Screen Media Review, 3, 84-99.

John, N. A. (2012). Sharing and web 2.0: The emergence of a keyword. New Media \& Society, 15(2), 167-182. doi:10.1177/1461444812450684

John, N. A. (2013). The social logics of sharing. The Communication Review, 16(3), 113-131. doi:10.1080/10714421.2013.807119

Katz, M. L., \& Shapiro, C. (1986). Production compatibility choice in a market with technological progress. Oxford Economic Papers, 38, 146-165.

doi:10.1093/oxfordjournals.oep.a041761

Kwon, K. (2011). A network approach to Web 2.o social influence: The influentials, word-ofmouth (WOM) effect, and the emergence of social network on Facebook. Doctoral Dissertation. State University of New York at Buffalo.

Lessig, L. (2008). Remix: Making art and commerce thrive in the hybrid economy. London: Bloomsbury Academic.

Madrigal, A. C. (2014, 2 January). How Netflix Reverse Engineered Hollywood. The Atlantic. Retrieved from

http://www.theatlantic.com/technology/archive/2014/o1/how-netflix-reverse-engineered-holly wood/282679/.

Mansell, R. \& Steinmueller, E. W. (2013). Copyright infringement online: The case of the Digital Economy Act judicial review in the United Kingdom. New Media \& Society, 15(8), 1312-1328. doi:10.1177/1461444812470429

Noam, E. M. \& Pupillo, L. M. (Eds.). (2008). Peer-to-peer video. The economics, policy, and culture of today's new mass medium. New York: Springer.

Pagani, M. \& Mirabello, A. (2011). The influence of personal and social-interactive engagement in social TV web sites. International Journal of Electronic Commerce, 16(2), 41-68.

doi:10.2753/JEC1086-4415160203

Reed, D. P. (2001). The law of the pack. Harvard Business Review, 79(2), 23-24.

Rifkin, J. (2014). The zero marginal cost society: The Internet of things, the collaborative commons, and the eclipse of capitalism. New York: Palgrave Macmillan. 
Rohlfs, J. (1974). A theory of interdependent demand for a communication service. Bell Journal of Economics, 5, 16-37. doi:10.2307/300309o

Rohn, U. (2004). Media companies and their strategies in foreign television markets.

Retrieved from http://www.rundfunk-institut.uni-koeln.de/institut/pdfs/18704.pdf

Rohn, U. (2013). Social networking sites across cultures and countries: Proximity and network effects. Qualitative Research Reports in Communication, 14(1), 28-34.

doi:10.1080/17459435.2013.835339

Rohn, U. \& Baumann, S. (2015). Media brands in social network sites: Problems German media companies have faced and lessons they have learned. Journal of Brand Strategy, 4(1), 70-82.

Rohn, U. \& Nylund, M. (2016). Keyword 'Sharing Economy': A growing sharing culture and its replications in changing business models of TV providers. Paper presented at the World Media Economics and Management Conference, New York, USA.

Rosen, D., Lafontaine, P.R., \& Hendrickson, B. (2011). CouchSurfing: Belonging and trust in a globally cooperative online social network. New Media \& Society, 13(6), 981-998.

doi:10.1177/1461444810390341

Slee, T. (2015). What's yours is mine: Against the Sharing Economy. New York and London: OR Books.

Spangler, T. (2015, 13.06). Ted Sarandos: Netflix Appetite for Originals Growing Stronger. Variety. Retrieved from

http://variety.com/2015/digital/news/netflix-ted-sarandos-original-series-1201494618/

Terranova, T. (2004). Network Culture: Politics For the Information Age. London: Pluto Press.

Von Hippel, E. (2005). Democratizing Innovation. Cambridge, MA: MIT Press. Available at https://mitpress.mit.edu/books/democratizing-innovation

Vonderau, P. (2015). The Politics of Content Aggregation. Television \& New Media, 16(8), 717733. doi:10.1177/1527476414554402

Vonderau, P. (2016). The Video Bubble: Multi-Channel Networks and the Transformation of Youtube. Convergence, 22(3). doi:10.1177/1354856516641882

\section{FOOTNOTES}

1. Public consultation on the regulatory environment for platforms, online intermediaries, data and cloud computing and the collaborative economy. URL: https://ec.europa.eu/digitalagenda/en/news/public-consultation-regulatory-environment-platforms-onlineintermediaries-data-and-cloud

2. URL: https://ec.europa.eu/digital-agenda/en/news/contributions-and-preliminary-trendspublic-consultation-audiovisual-media-services-avmsd 